\title{
Addressing the Negative Self-Concept in Posttraumatic Stress Disorder by a Three-Session Programme of Cognitive Restructuring and Imagery Modification (CRIM-PTSD): A Case Study
}

\author{
Meike Müller-Engelmann*, Kerstin Hadouch, Regina Steil \\ Department of Clinical Psychology and Psychotherapy, Institute of Psychology, Goethe University Frankfurt Main, \\ Frankfurt/Main, Germany \\ Email: *mueller-engelmann@psych.uni-frankfurt.de, hadouch@therapie-badhomburg.de, steil@psych.uni-frankfurt.de
}

How to cite this paper: Müller-Engelmann, M., Hadouch, K. and Steil, R. (2018) Addressing the Negative Self-Concept in Posttraumatic Stress Disorder by a Three-Session Programme of Cognitive Restructuring and Imagery Modification (CRIM-PTSD): A Case Study. Journal of Behavioral and Brain Science, 8, 319-327.

https://doi.org/10.4236/jbbs.2018.85020

Received: March 14, 2018

Accepted: May 25, 2018

Published: May 28, 2018

Copyright $(0) 2018$ by authors and Scientific Research Publishing Inc. This work is licensed under the Creative Commons Attribution International License (CC BY 4.0).

http://creativecommons.org/licenses/by/4.0/

\begin{abstract}
Background: Cognitive restructuring and imagery modification for posttraumatic stress disorder (CRIM-PTSD) is a new intervention that involves only three sessions and focuses on the self-concept. It combines cognitive restructuring of core trauma-related dysfunctional beliefs and mental imagery. The effectiveness of CRIM-PTSD has recently been demonstrated in a pilot study. Method: This article presents a step-by-step description of the administration of CRIM-PTSD in a female survivor of childhood sexual abuse (CSA) suffering from PTSD and major depressive disorder related to strong self-blame. Results: The intervention showed substantial reductions in PTSD symptoms and depression in the patient comparable to those observed in the pilot study. Conclusions: CRIM-PTSD might provide an economical tool for reducing PTSD symptoms when only a short time is available for intervention. Furthermore, this tool could be included in well-established PTSD treatments. In addition to the pilot study, a randomized controlled trial is needed to further explore the feasibility and effectiveness of this short intervention.
\end{abstract}

\section{Keywords}

Posttraumatic Stress Disorder, Cognitive Restructuring, Imagery, Self-Concept 


\section{Introduction}

Trauma-related cognitive alterations, which were included as a new diagnostic criterion for PTSD in the DSM-5 [1], play an important role in the development and maintenance of PTSD [2]. Among those, negative cognitions about the self (e.g., being incompetent and helpless) seem to be especially important as the trauma represents a threat to the integrity of the self [3]. More concretely, PTSD has been hypothesized to be maintained by a substantial negative transformation of the original self-concept via self-defining memories of the traumatic event [4], and a vicious cycle of negative cognitions about the self and PTSD symptoms has been postulated [5]. Correspondingly, empirical data show that the majority of the cognitions associated with intrusive images are related to psychological threat to one's sense of self [6] and that considering the trauma central to one's identity leads to greater PTSD severity [7], [8].

A combination of mental imagery and cognitive techniques has been proven effective in the treatment of different disorders, such as depression [9] and social anxiety disorder [10]. Regarding the treatment of PTSD, recent data suggest that both cognitive [11] and imagery interventions [12] are particularly effective. Furthermore, there is a need for new short interventions for PTSD as affected patients, despite their intense suffering, often wait a very long time to find adequate help [13].

Cognitive restructuring and imagery modification (CRIM) is one such new short intervention. It was first developed to address the feeling of being contaminated [14], which can be considered a possible negative transformation of the self-concept in victims of sexual abuse. CRIM combines cognitive restructuring (information about the regular renewal of human skin) with imagery modification by finding an individualized image of the renewal [15]. In a randomized, wait-list controlled trial, Jung and Steil [16] found that CRIM had strong effects on PTSD symptoms.

One explanation for these strong effects is that mental imagery is similar to actual experience [17]; therefore, it strengthens the effect of cognitive interventions. Furthermore, mental imagery has been postulated to be especially powerful in influencing emotions, and cognitions "in the form of an image rather than a verbal thought will be associated with stronger emotion" ([18], p. 299).

Regarding these strong effects, CRIM was amplified to treat PTSD more generally in patients who suffer from different negative self-concepts, e.g., from the idea of being worthless or helpless, and who may have experienced traumatic events other than sexual abuse [19]. A pilot study with ten patients provided preliminary evidence that CRIM-PTSD can be used to effectively reduce PTSD symptoms [20], and large pre-intervention to follow-up effect sizes were found for clinician-rated $(d=2.53)$ and self-reported $(d=1.45)$ PTSD symptoms.

In the following, we describe the new intervention and present a step-by-step description of its application. 


\section{Method}

\subsection{Description of CRIM-PTSD}

The intervention comprises two treatment sessions (each 90 minutes) and a booster session (50 minutes). This design was chosen to correspond to the previously developed intervention designed to address the feeling of being contaminated [14]. One advantage of the 90 -minute treatment sessions is that it allows time to address the relevant topics more deeply than shorter sessions would.

First session. The therapist explores the distressing negative self-concept and its relation to the traumatic event(s) by asking the patient what she thinks about herself as somebody who experienced that particular trauma. Afterwards, the most central trauma-related dysfunctional assumption regarding the self is defined. Subsequently, this assumption is questioned by using various cognitive techniques, e.g., Socratic questioning and the devil's advocate technique. The devil's advocate technique, for example, aims to reduce feelings of guilt concerning why or how the trauma occurred and involves asking the patient why she acted the way she did before or during the trauma ("You believe that your father abused you because you are a bad person. How did you make your father abuse you? Why did you sit on his lap?"). The role of the patient in the traumatic events is addressed, as well as the current validity of the assumption. Because central negative self-concepts differ among patients and traumas, the procedure is individually adapted. As homework, the patients write a defence against the trueness of the central dysfunctional assumption and read it every day.

Second session. At the beginning of the second session, the therapist explains that mental imagery is a powerful technique for changing feelings in addition to considering rational reasons, as in the previous session. Subsequently, the patient is asked to develop an individual image that represents his/her negative self-concept and a way to change it to a positive one. During this process, the therapist asks about sensory details such as colours, smells and sounds to make both images, and especially the positive one, more vivid and real to better connect to the patients' emotions. Afterwards, in the imagery exercise the patient is asked to bring the negative self-image to his/her attention and then to change it into the positive one. After the session, the patient receives an audiotape of the imagery work to practice it every day at home.

Third treatment session. The booster session has the following aims: to reflect the patient's progress, to address problems with the homework exercises and to find strategies for integrating the learned techniques into the patient's daily life.

\subsection{Measurements}

In our case example, Axis I diagnosis and PTSD severity were assessed prior to treatment $\left(\mathrm{t}_{0}\right)$ by a trained clinician according to the Structured Clinical Interview for the DSM-IV [21]. 
To assess PTSD symptoms, the Clinician-Administered PTSD Scale (CAPS) [22] was used. The CAPS is a semi-structured interview that measures the frequency and intensity of 17 PTSD symptoms over the past 4 weeks. The sum score ranges from 0 to 136 . The CAPS interview was administered prior to treatment $\left(\mathrm{t}_{0}\right)$ and 4 weeks after the intervention $\left(\mathrm{t}_{2}\right)$ by a trained clinician.

As a self-report measure of PTSD symptoms, the Posttraumatic Stress Diagnostic Scale (PDS) [23] was used. The PDS assesses the severity of the 17 PTSD symptoms over the past month. The total symptom severity score ranges from 0 to 51 . The PDS was administered prior to treatment $\left(t_{0}\right)$, post-treatment $\left(t_{1}\right)$, and 4 weeks after the intervention $\left(t_{2}\right)$.

To assess depressive symptoms, the Beck Depression Inventory II (BDI-II) [24] was used. The BDI is a 21-item questionnaire that measures depressive symptoms over the past two weeks. The total score ranges from 0 to 63 . The BDI was administered prior to treatment $\left(t_{0}\right)$, post-treatment $\left(t_{1}\right)$, and 4 weeks after the intervention $\left(t_{2}\right)$.

\subsection{Case Report}

History. Susan is a 22-year-old student who experienced CSA by her swimming teacher at the ages of 9 and 10 years. In the beginning, she was very proud when the swimming teacher offered her private lessons. Later, when he started to touch her, she was afraid. After he raped her at a swimming camp, she quit the lessons. Shortly thereafter, PTSD symptoms and symptoms of anorexia nervosa emerged.

At $t_{0}$, she was diagnosed with PTSD, recurrent major depressive disorder (currently mild), bulimia nervosa and symptoms of borderline personality disorder. From the ages of 14 to 19 years, she had received behaviour therapy focusing on her eating disorder.

Susan's central dysfunctional assumption was that she was responsible for the CSA. She thought that it had occurred because she was a bad person and that having sexual relationships with young men after flirting with them in the present was also proof of her bad character.

First treatment session. The idea of being a bad person and its link to the CSA were analysed. Susan argued that she had provoked the abuse because she had enjoyed the attention of her swimming teacher and had tried to be near him during training. She thought her behaviour at the time had been similar to that of an adult flirting with somebody. However, the analysis of her motives clarified that she had been interested in being good at swimming and not aspiring towards a sexual relationship. When she was asked to think about other children of the same age, she reasoned that her behaviour had been quite normal for a 9-year-old girl who was very engaged in sports. Furthermore, it became clear that the teacher had been the active participant because, for example, he had told her that he had to examine her body to determine whether everything was okay for swimming. 
The second part of the session was dedicated to reviewing Susan's belief that she was a bad person because of how she initiated sexual relationships in the present. She thought that she was manipulating men by flirting with them and by trying to impress them with her physical appearance. Further analysis revealed that her behaviour was a normal adult interaction that did not damage anyone and that the idea that it was not acceptable resulted from her history with the swimming teacher, who had made her feel responsible for the abuse.

Susan then wrote a plea explaining why she had not been responsible for the CSA and why it was okay for her to flirt in the present.

Second treatment session. Susan explained that the most important point for her in the first session had been to understand that the swimming teacher was responsible for the abuse as children act without any sexual intention. To symbolize her negative self-concept, she chose the image of a small girl who seems to be innocent but can nonetheless do a great deal of harm. She described this girl as having vicious eyes ("because you see the character of a person in their eyes") and a feminine body-a disguised adult woman in the clothes of a child, tricking others. She compared it with a movie that she had seen in which a 40 -year-old woman with the appearance of a child seduced her foster father. To illustrate this girl's bad character, she imagined her to have dirty skin under her clothes and as being excluded from all other people.

When asked to change this image into a positive one, she started the modification with the idea of rain, which washes away the false clothes, the dirt and the evil expression. Because she felt uncomfortable in a feminine body, she wanted the rain to remove femininity too. After clarifying again that femininity was not the cause of the abuse, she determined that a physical activity could help her feel better in a feminine body and included swimming in the sea in her image. The therapist first wondered whether swimming could be a positive activity for her. However, Susan explained that she had always loved swimming and that it was really beneficial to reclaim this activity. Because it was important to her to include being in touch with others in her positive image, she imagined that when she finished swimming, she alighted on an island, where she met her friends.

After elaborating this sequence, the therapist guided Susan through these images. Susan managed to focus on the imagery very well and amplified it with more details, such as eating pancakes with her friends, something that she normally would never do. At the end, she was asked to practice this imagery every day.

Third session. Susan explained that she had listened to the entire tape of the imagery only twice because it was stressful for her to hear her own voice. Nevertheless, she had found a way to further integrate imagery into her daily routine by adding a short version (imagining the rain, the swimming and the being with friends) at the end of her daily yoga exercises.

Further analysis revealed that her negative self-image often emerged during contact with peers and that thinking about the reasons she was not at fault in the 
swimming teacher's abuse could help her manage these situations better. Furthermore, she remembered a song that her aunt had often sung when she was a child. This song symbolized to her the possibility of being in harmony with others and therefore could activate the power of the positive imagery when she was feeling guilty during contact with others.

\section{Results}

At the end of the intervention, Susan explained that the rational arguments against her guilt and the process of developing the imagery had been especially important.

Her CAPS intensity scores were reduced from 78 (severe PTSD) at $t_{0}$ (baseline) to 51 (medium PTSD) at $t_{2}$ (4 weeks after the intervention). Figure 1 shows the reduction in the self-report measures. The PDS total severity score was reduced from 31 (moderate to severe PTSD) at $t_{0}$ to 21 (moderate to severe PTSD) at $t_{2}$. Furthermore, there was a relevant reduction of depression: the BDI total score was reduced from 34 (severe depression) at $t_{0}$ to 13 (mild depression) at $t_{2}$.

\section{Discussion}

This case study illustrates the use of CRIM-PTSD, a newly developed short intervention to reduce PTSD symptoms by addressing dysfunctional negative self-concepts. After cognitive restructuring during this intervention, the central negative self-concept is activated by finding a corresponding negative image, which is then transformed to a more positive image. Going beyond the use of CRIM to address the feeling of being contaminated [14], this case study illustrates how CRIM may be used to reduce PTSD symptoms in patients who suffer from distressing negative self-concepts other than the feeling of being contaminated. The results of a pilot study [20] show strong pre-follow-up reductions in PTSD symptoms and trauma-related negative cognitions regarding the self as well as depressive symptoms.

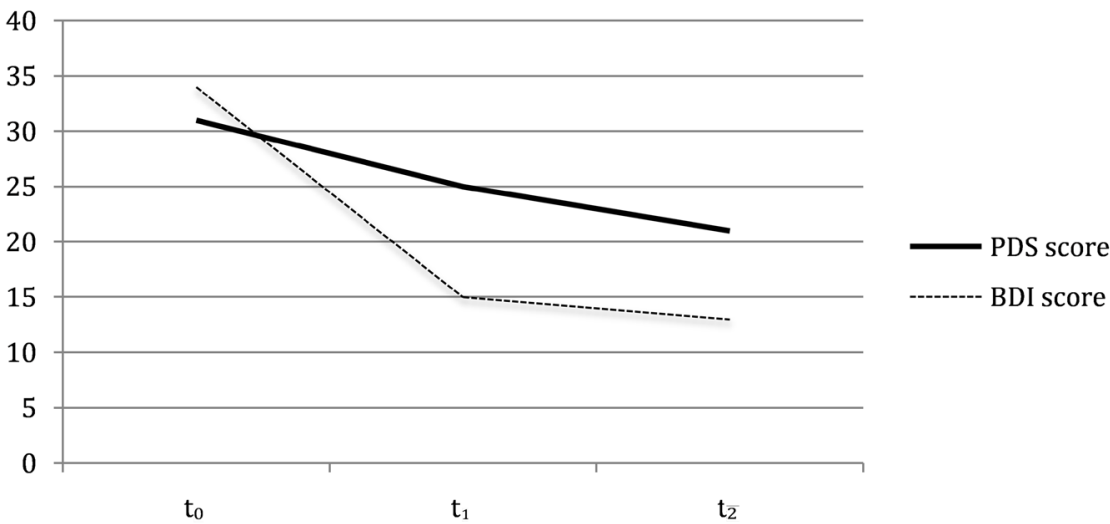

Figure 1. Susan's self-reported posttraumatic stress disorder and depressive symptoms. PDS $=$ Posttraumatic Stress Diagnostic Scale, BDI $=$ Beck Depression Inventory II, $\mathrm{t}_{0}=$ prior to treatment, $t_{1}=$ post-treatment, $t_{2}=4$ weeks after the intervention. 
CRIM-PTSD differs from interventions that work with intrusive memories in PTSD (e.g., [25]) insofar that this intervention does not address or change the trauma memory directly. Instead, it works with a negative core belief that resulted from the traumatic situation and transforms this belief into a mental image to better address the underlying emotions.

CRIM-PTSD may be used to archive rapid initial improvements within a short period of time. In the described patient, rapid substantial reductions in PTSD and depressive symptoms were observed; nevertheless, the patient will likely need further treatment to address the remaining symptoms. Furthermore, the intervention may be used as a first therapeutic step to increase treatment motivation or may be included in the course of longer, well-established PTSD treatments (e.g., [26]).

As the presented intervention must be individually tailored to each patient's dysfunctional self-concept, therapists must be trained and experienced in cognitive therapies and sufficiently skilled to address the trauma-related central dysfunctional assumption regarding the self.

In addition to our pilot study [20], randomized controlled trials are needed to further evaluate the effectiveness of CRIM-PTSD by addressing negative self-concepts in a larger sample of PTSD patients.

\section{Compliance with Ethical Standards}

This study was approved by the ethics committee of Goethe University, Frankfurt, Germany. All procedures performed in this study involving human participants were in accordance with the ethical standards of the institutional research committee and with the 1964 Helsinki declaration and its later amendments or comparable ethical standards. Informed consent was obtained from all individual participants included in the study.

\section{References}

[1] American Psychiatric Association (2013) Diagnostic and Statistical Manual of Mental Disorders. 5th Edition, American Psychiatric Association, Arlington.

[2] Ehlers, A. and Clark, D.M. (2000) A Cognitive Model of Posttraumatic Stress Disorder. Behaviour Research and Therapy, 38, 319-345. https://doi.org/10.1016/S0005-7967(99)00123-0

[3] Grey, N. (2009) Imagery and Psychological Threat to the Self in PTSD. In: Stopa, S., Ed., Imagery and the Threatened Self. Perspectives on Mental Imagery and the Self in Cognitive Therapy, Routledge, London, 137-165.

[4] Cili, S. and Stopa, L. (2015) Intrusive Mental Imagery in Psychological Disorders: Is the Self the Key to Understanding Maintenance? Frontiers in Psychiatry, 6, 103. https://doi.org/10.3389/fpsyt.2015.00103

[5] Shahar, G., Noyman, G., Schnidel-Allon, I. and Gilboa-Schechtman, E. (2013) Do PTSD Symptoms and Trauma-Related Cognitions about the Self Constitute a Vicious Cycle? Evidence for Both Cognitive Vulnerability and Scarring Models. Psychiatry Research, 205, 79-84. https://doi.org/10.1016/j.psychres.2012.07.053

[6] Holmes, E.A., Gery, N. and Young, K.A.D. (2005) Intrusive Images and "Hotspots" 
of Trauma Memories in Posttraumatic Stress Disorder. An Exploratory Investigation of Emotions and Cognitive Themes. Journal of Behavior Therapy and Experimental Psychiatry, 36, 3-17. https://doi.org/10.1016/j.jbtep.2004.11.002

[7] Berntsen, D. and Rubin, D.C. (2006) The Centrality of Event Scale: A Measure of Integrating a Trauma into One's Identity and Its Relation to Posttraumatic Stress Disorder Symptoms. Behaviour Research and Therapy, 44, 219-231. https://doi.org/10.1016/j.brat.2005.01.009

[8] Robinaugh, D.J. and McNally, R.J. (2011) Trauma Centrality and PTSD Symptom Severity in Adult Survivors of Childhood Sexual Abuse. Journal of Traumatic Stress, 24, 483-486. https://doi.org/10.1002/jts.20656

[9] Wheatley, J., Brewin, C.R., Patel, T., Hackmann, A., Wells, A., et al. (2007) "I'll Believe It When I Can See it": Imagery Rescripting of Intrusive Sensory Memories in Depression. Journal of Behavior Therapy and Experimental Psychiatry, 38, 371-385. https://doi.org/10.1016/j.jbtep.2007.08.005

[10] Wild, J. and Clark, D.M. (2011) Imagery Rescripting of Early Traumatic Memories in Social Phobia. Cognitive and Behavioral Practice, 18, 433-443.

https://doi.org/10.1016/j.cbpra.2011.03.002

[11] Cusack, K., Jonas, D.R., Forneris, C.A., Wines, C., Sonis, J., et al. (2016) Psychological Treatments for Adults with Posttraumatic Stress Disorder: A Systematic Review and Meta-Analysis. Clinical Psychology Review, 43, 128-141.

https://doi.org/10.1016/j.cpr.2015.10.003

[12] Morina, N., Lancee, J. and Arntz, A. (2016) Imagery Rescripting as a Clinical Intervention for Aversive Memories: A Meta-Analysis. Journal of Behavioural Therapy and Experimental Psychiatry, 9, 6-15.

[13] Kazlauskas, E., Javakhishvilli, J., Meewisse, M., Merecz-Kot, D., Şar, V., et al. (2016) Trauma Treatment across Europe: Where Do We Stand Now from a Perspective of Seven Countries. European Journal of Psychotraumatology, 7, 29450. https://doi.org/10.3402/ejpt.v7.29450

[14] Steil, R., Jung, K. and Stangier, U. (2011) Efficacy of a Two-Session Program of Cognitive Restructuring and Imagery Modification to Reduce the Feeling of Being Contaminated in Adult Survivors of Childhood Sexual Abuse: A Pilot Study. Journal of Behavior Therapy and Experimental Psychiatry, 42, 325-329. https://doi.org/10.1016/j.jbtep.2011.01.008

[15] Jung, K., Dyer, A., Priebe, K., Stangier, U. and Steil, R. (2011) Das Gefühl des Beschmutztseins bei erwachsenen Opfern sexualisierter Gewalt in Kindheit und Jugend. Verhaltenstherapie, 21, 247-253. https://doi.org/10.1159/000333389

[16] Jung, K. and Steil, R. (2013) A Randomized Controlled Trial on Cognitive Restructuring and Imagery Modification to Reduce the Feeling of Being Contaminated in Adult Survivors of Childhood Sexual Abuse Suffering from Posttraumatic Stress Disorder. Psychotherapy and Psychosomatics, 82, 213-220. https://doi.org/10.1159/000348450

[17] Arntz, A. (2012) Imagery Rescripting as a Therapeutic Technique: Review Oo Clinical Trials, Basic Studies, and Research Agenda. Journal of Experimental Psychopathology, 3, 189-208. https://doi.org/10.5127/jep.024211

[18] Holmes, E.A., Arntz, A. and Smucker, M.R. (2007) Imagery Rescripting in Cognitive Behaviour Therapy: Images, Treatment Techniques and Outcomes. Journal of Behavior Therapy and Experimental Psychiatry, 38, 297-305. https://doi.org/10.1016/j.jbtep.2007.10.007

[19] Steil, R., Benner, A., Müller-Engelmann, M. and Hadouch, K. (2015) Cognitive Re- 
structuring and Imagery Modification. Psychotherapeut, 60, 310-314.

https://doi.org/10.1007/s00278-015-0041-8

[20] Müller-Engelmann, M. and Steil, R. (2016) Cognitive Restructuring and Imagery Modification for Posttraumatic Stress Disorder (CRIM-PTSD): A Pilot Study. Journal of Behavior Therapy and Experimental Psychiatry, 54, 44-50.

https://doi.org/10.1016/j.jbtep.2016.06.004

[21] Wittchen, H.U., Wunderlich, U., Gruschwitz, S. and Zaudig, M. (1997) SKID. Strukturiertes Klinisches Interview für DSM-IV Achse I. Hogref, Göttingen.

[22] Schnyder, U. and Moergeli, H. (2002) German Version of Clinician-Administered PTSD Scale. Journal of Traumatic Stress, 15, 487-492. https://doi.org/10.1023/A:1020922023090

[23] Griesel, D., Wessa, M. and Flor, H. (2006) Psychometric Qualities of the German Version of the Posttraumatic Diagnostic Scale (PTDS). Psychological Assessment, 18, 262-268. https://doi.org/10.1037/1040-3590.18.3.262

[24] Hautzinger, M., Bailer, M., Worall, A. and Keller, F. (2006) Beck-Depressions-Inventar (BDI). Hans Huber, Bern.

[25] Arntz, A., Tiesema, M. and Kindt, M. (2007) Treatment of PTSD: A Comparison of Imaginal Exposure with and Without Imagery Rescripting. Journal of Behavior Therapy and Experimental Psychiatry, 38, 345-370. https://doi.org/10.1016/j.jbtep.2007.10.006

[26] Ehlers, A., Clark, D.M., Hackmann, A., McManus, F. and Fennell, M. (2005) Cognitive Therapy for Post-Traumatic Stress Disorder: Development and Evaluation. Behaviour Research and Therapy, 43, 413-431.

https://doi.org/10.1016/j.brat.2004.03.006 